\title{
A Case of Giant Hydronephrosis Hidden by Obesity in an 11-year-old Boy
}

\section{Gumbich Hwang, M.D. ${ }^{1}$ \\ Inchan Hwang, M.D. ${ }^{1}$ \\ Seol Ho Choo, M.D. ${ }^{2}$ \\ Hyun Gi Kim, M.D. ${ }^{3}$ \\ Ki Soo Pai, M.D ${ }^{1}$}

Department of Pediatrics', Department of Urology ${ }^{2}$, Department of Radilogy ${ }^{3}$, Ajou University School of Medicine, Suwon, Korea

\section{Corresponding author: \\ Ki Soo Pai, M.D., Ph.D. \\ Department of Pediatrics, Ajou University \\ School of Medicine, 164, World cup-ro, \\ Yeongtong-gu, Suwon-si, Gyeonggi-do \\ 16499, Korea \\ Tel: +82-31-219-5169 \\ Fax: +82-31-219-5160 \\ E-mail:kisoopai@ajou.ac.kr}

Received: 15 August 2017

Revised: 18 September 2017

Accepted: 27 September 2017
Giant hydronephrosis $(\mathrm{GH})$ is a rare urological entity and usually presents with more than a liter of fluid in the collecting system. It may mimic a progressive and benign abdominal cystic tumor. We report a case of GH in an 11-year-old obese boy who presented with abdominal distension and dyspnea on exercise. Hydronephrosis was caused by ureteropelvic junction obstruction, with 2,300 mL of fluid in the collecting system. Diagnostic and therapeutic features of this case are discussed, with reference to current literature.

Key words: Giant hydronephrosis, Obesity, Dyspnea, Abdominal distension

\section{Introduction}

Giant hydronephrosis (GH) is defined as a presence of more than 1 liter of urine in the collecting system ${ }^{1)}$. Ureteropelvic junction (UPJ) obstruction is a common cause of hydronephrosis during childhood, and other causes include stone disease, trauma, and renal ectopia. Although giant hydronephrotic kidney may occasionally be found from intra-abdominal mass, intermittent abdominal pain, or hematuria, it is mostly asymptomatic because hydronephrosis progresses slowly to a $\mathrm{GH}$ without any prominent symptoms ${ }^{2)}$.

More than 500 cases of $\mathrm{GH}$ have been reported ${ }^{3}$. $\mathrm{GH}$ is often misdiagnosed as another disease; only about $46 \%$ of 61 cases were diagnosed correctly ${ }^{4}$. In Korea, $7,000 \mathrm{ml}$ sized GH in an 8 year-old child has been reported without any symptoms of dyspnea ${ }^{5}$. In this study, we are adding an interesting case of GH in a boy who visited obesity clinic complaining of dyspnea on exercise (DOE) and abdominal distension mislead as abdominal obesity.

\section{Case report}

This is an open-access article distributed under the terms of the Creative Commons Attribution Non-Commercial License (http:// creativecommons.org/licenses/by-nc/4.0/) which permits unrestricted non-commercial use, distribution, and reproduction in any medium, provided the original work is properly cited.
An 11-year-old boy came to the hospital with a complaint of abdominal distension and DOE for years. The patient had a history of asthma during seasonal changes without according medication. The last respiratory symptom 2 weeks before visiting hospital was only coughing. He had abdominal distension and DOE continuously for 3 years and no recent aggravation. The parents visited our hospital for obesity-related health screenings because they thought 
the abdominal distension and DOE were caused by obesity. The patient usually overate and defecated immediately after food intake more than 3 times a day. No other specific urinary or bowel symptom was identified. Medical history was not remarkable except for seasonal asthma, including prenatal ultrasonography. Because he has been overweight since infancy, the parents assumed the abdominal distension and DOE were due to obesity.

The patient's height was $150 \mathrm{~cm}$ ( $75^{\text {th }}$ percentile $)$ and weight was $64 \mathrm{~kg}\left(>97^{\text {th }}\right.$ percentile $)$ with a BMI of $27.3 \mathrm{~kg} / \mathrm{m}^{2}\left(>97^{\text {th }}\right.$ percentile). Vital signs were BP 132/80 mmHg, PR 87 times/ min, RR 20 times $/ \mathrm{min}, \mathrm{BT} 37^{\circ} \mathrm{C}$. The physical examination showed clear lung sound and normal heart sound without murmur. There was a very tense abdominal distension, but no tenderness nor palpable mass. Laboratory blood tests were within normal range: BUN $14.4 \mathrm{mg} / \mathrm{dL}$, creatinine $0.62 \mathrm{mg} / \mathrm{dL}$, total protein $7.1 \mathrm{~g} / \mathrm{dL}$, albumin $4.4 \mathrm{~g} / \mathrm{dL}$, total cholesterol $161 \mathrm{mg} / \mathrm{dL}$. Urinalysis results were also within normal range: protein negative, $\mathrm{RBC} 0 / \mathrm{HPF}, \mathrm{WBC} 1 / \mathrm{HPF}$. Electrocardiogram showed normal sinus rhythm and rate. On chest $\mathrm{x}$-ray, compressed lungs and elevated diaphragm were revealed. Plain abdominal $\mathrm{x}$-ray revealed a huge masslike opacity occupying of the abdominal most entirely (Fig. 1). Ultrasonography revealed a large septated cystic lesion $\left(20.1 \times 13.6 \mathrm{~cm}^{2}\right)$ from the left-side to the midline of the abdomen (Fig. 2). The left kidney was not clearly delineated due to the abnormal size of the cystic mass. The right kidney was normal.

A computerized tomography (CT) scan revealed a severe hydronephrotic change of the left kidney, with markedly dilated renal pelvis and calyces with thinning of renal parenchyma (Fig. 3). Right kidney and urinary bladder were not remarkable. 99mTc-mercaptoacetyltriglycine (MAG3) renal scintigraphy revealed a significantly decreased perfusion to the left kidney and a delayed radioisotope uptake up to 50 minutes. Perfusion, uptake and excretion of right kidney were normal (Fig. 4). On 99mTc-dimercaptosuccinic acid (DMSA) renal scintigraphy, minimal parenchymal activity was found along the margin of huge cystic left kidney. The right kidney had no remarkable findings (Fig. 5).

On the basis of imaging studies, we came to a diagnosis of $\mathrm{GH}$ of left kidney with minimal residual renal function.

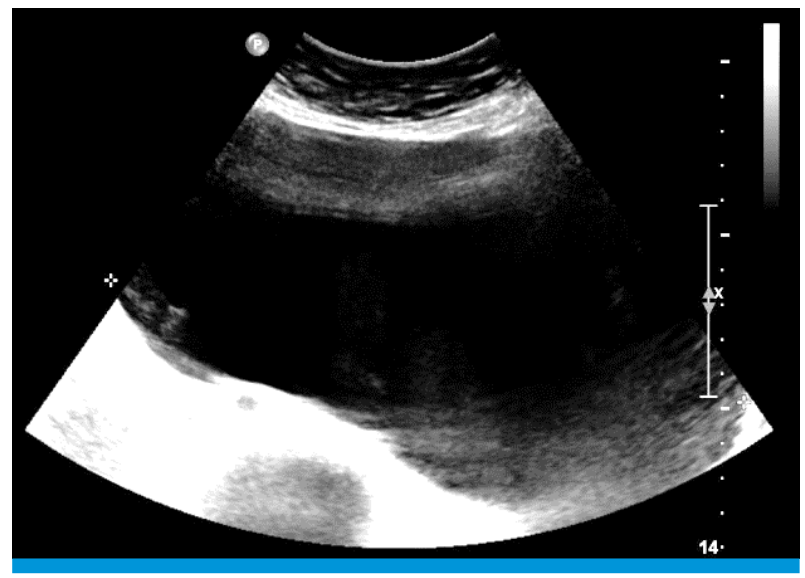

Fig. 2. Abdominal ultrasonographyrevealinga giant hydronephrotic mass $\left(20.1 \times 13.6 \mathrm{~cm}^{2}\right)$, which was not detectable during physical examination.

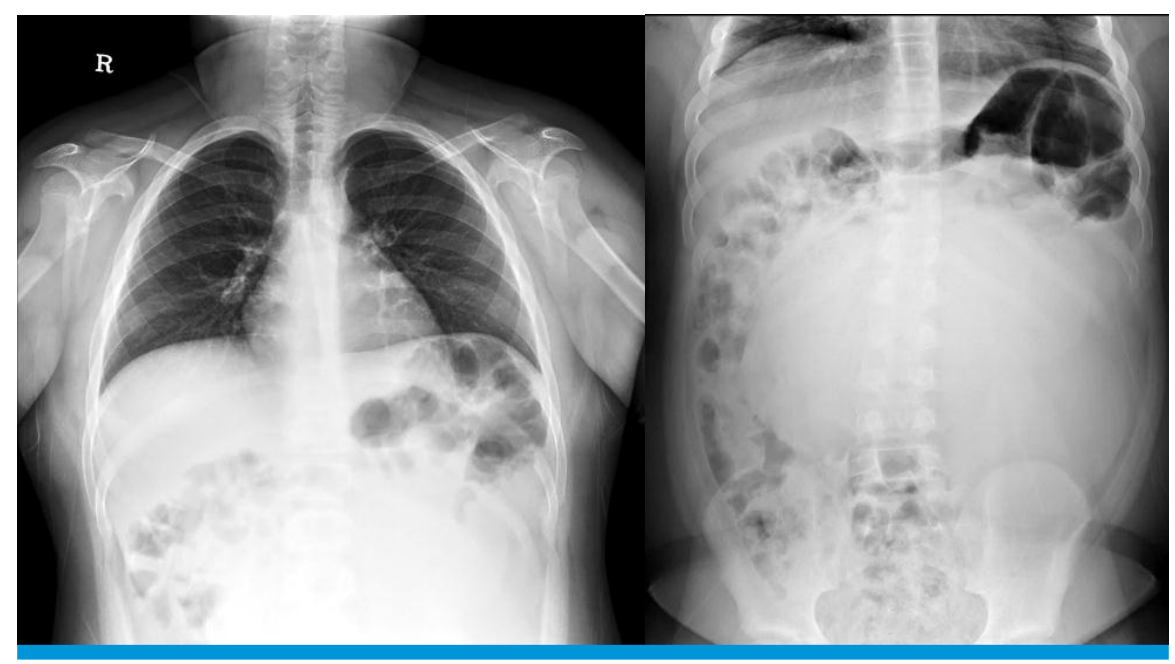

Fig. 1. Simple x-ray showing compressed lungs and elevation of diaphragm caused by a huge opaque mass occupying almost the entire abdomen. 
Nephrectomy was performed by laparoscopic surgery. The hydronephrotic kidney had an extremely thinned cortex from a massive cystic change containing approximately 2,300 $\mathrm{mL}$ of fluid, and there was no adhesion with adjacent organs. UPJ obstruction was confirmed as the cause of the hydronephrosis. The dimensions of the left kidney were $17 \times 17 \times 1.5 \mathrm{~cm}^{3}$, weighing $352 \mathrm{~g}$. The pathological specimens are shown in Fig. 6.

The patient was discharged on the $5^{\text {th }}$ day of operation with body weight loss of $4 \mathrm{~kg}$ without any complications. Three months after the surgery, the patient's height and

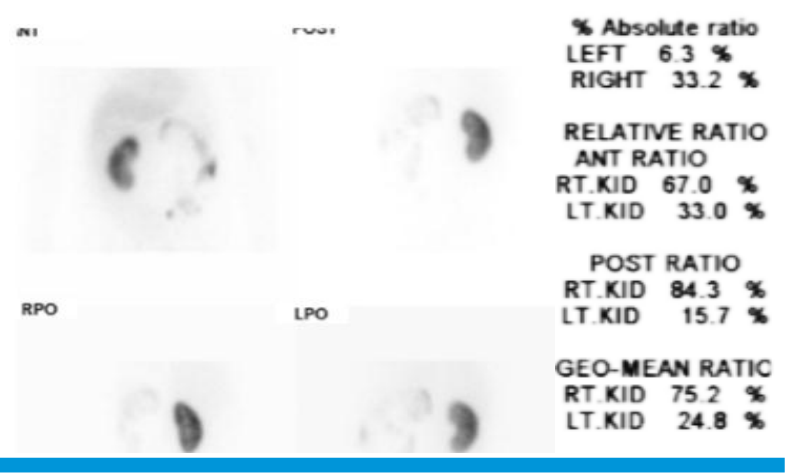

Fig. 5. ${ }^{99 \mathrm{~m}} \mathrm{Tc}-\mathrm{DMSA}$ renal scan showing minimal parenchymal activity on a margin of huge cystic left kidney.

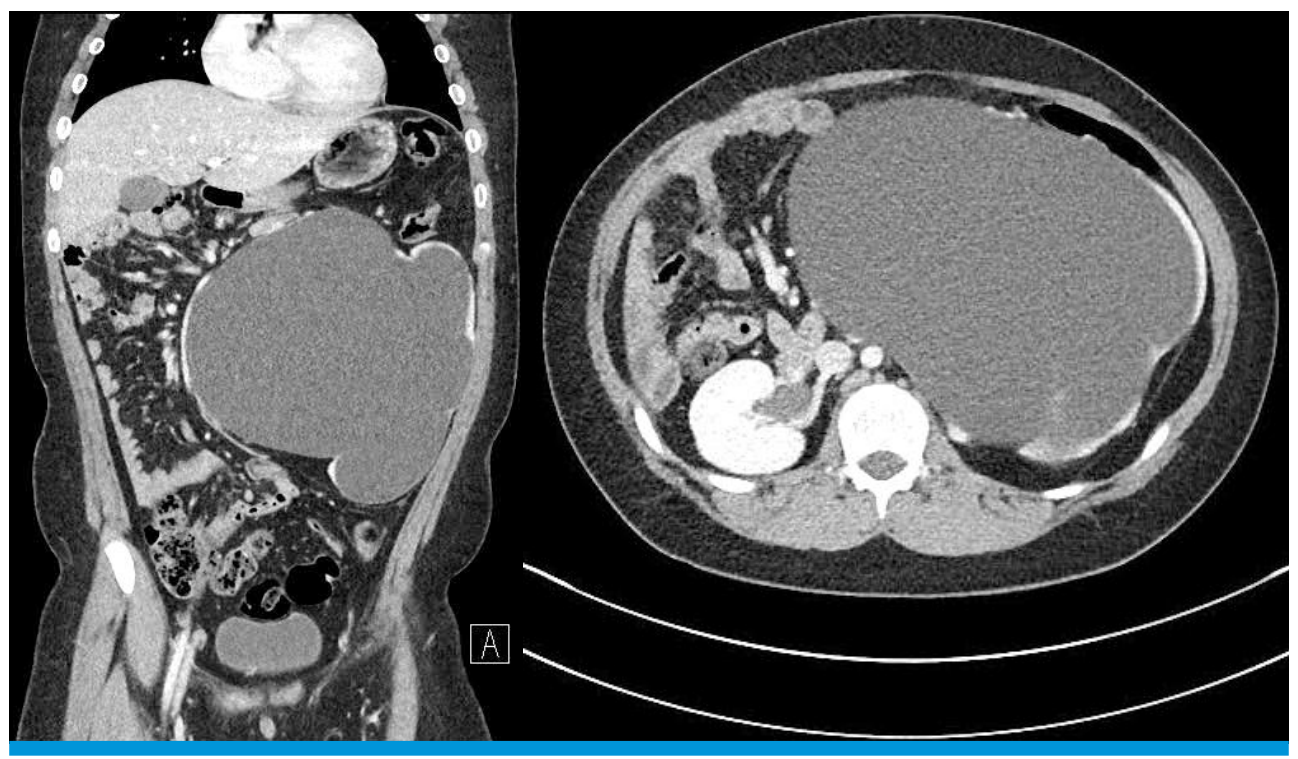

Fig. 3. Abdominal CT showing a huge hydronephrotic change of the left kidney with a thin renal parenchyma remaining along the cystic wall.

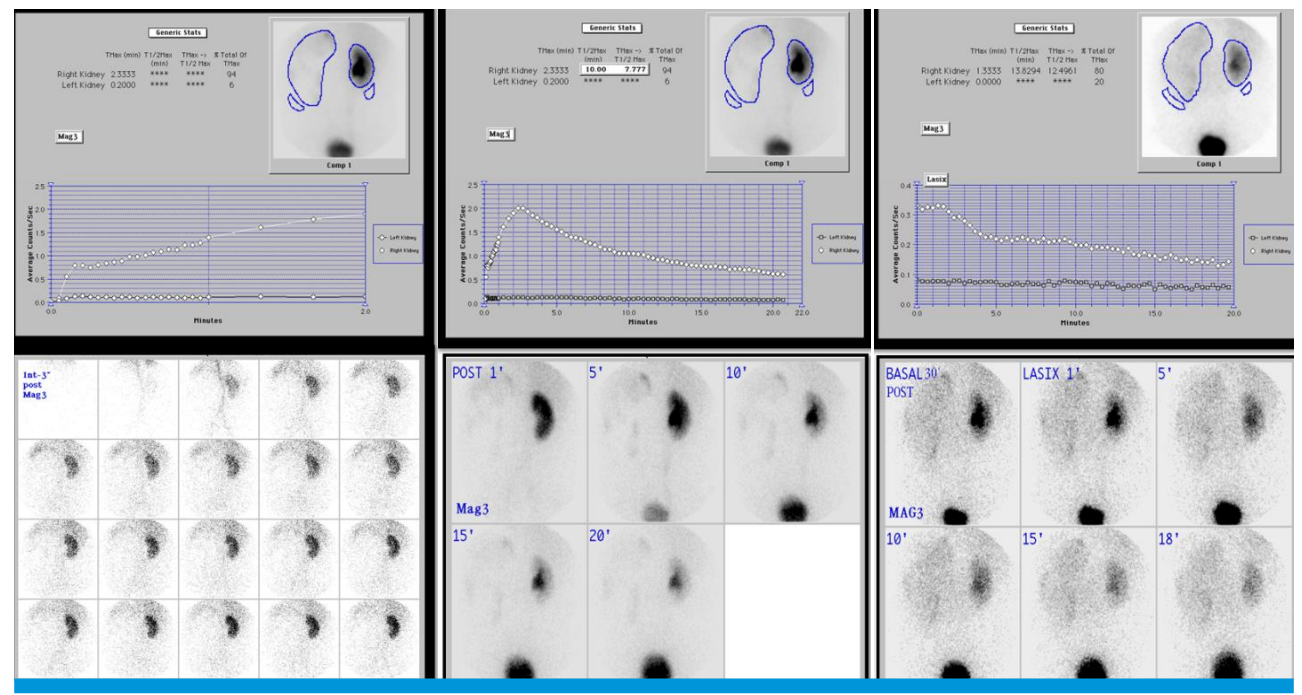

Fig. 4. Diuretic renogram with ${ }^{99 \mathrm{~m}} \mathrm{Tc}-\mathrm{MAG} 3$ scan showing markedly decreased perfusion to the left kidney and delayed radioisotope uptake over 50 minutes. 
weight were measured $150 \mathrm{~cm}\left(>75^{\text {th }}\right.$ percentile $)$ and $57 \mathrm{~kg}$ (90-95 ${ }^{\text {th }}$ percentile), respectively, with BMI of $24.3 \mathrm{~kg} / \mathrm{m}^{2}$ $\left(>90^{\text {th }}\right.$ percentile). He is no longer complaining about abdominal distension, DOE, and abnormal bowel habits.

\section{Discussion}

Giant hydronephrosis is a rare urological entity in patients of all ages, defined as the presence of more than 1 liter or $1.6 \%$ of body weight of fluid in the collecting system ${ }^{1,6)}$. The causes of urinary tract obstruction include UPJ obstruction, ureterovesical junction obstruction, obstructed upper half of a duplex kidney with ectopic ureterocele, and posterior urethral valve ${ }^{6}$. Though the most common cause of GH is UPJ obstruction, stone disease, trauma, renal ectopy and ureteral tumor have also been reported ${ }^{7,8)}$. The etiology of this case also belongs to UPJ obstruction.

$\mathrm{GH}$ is a slow progressive disease and may be presented with vague symptoms such as nausea, fatigue, dyspepsia, urinary tract infection, or gross hematuria ${ }^{9)}$. Neonate and infants with UPJ obstruction commonly present with a diagnosis through prenatal sonography ${ }^{10}$. Older children with UPJ obstruction can cause intermittently severe or recurrent abdominal pain ${ }^{11)}$. In a study of school-aged children, UPJ obstruction was found to be the cause of recurrent

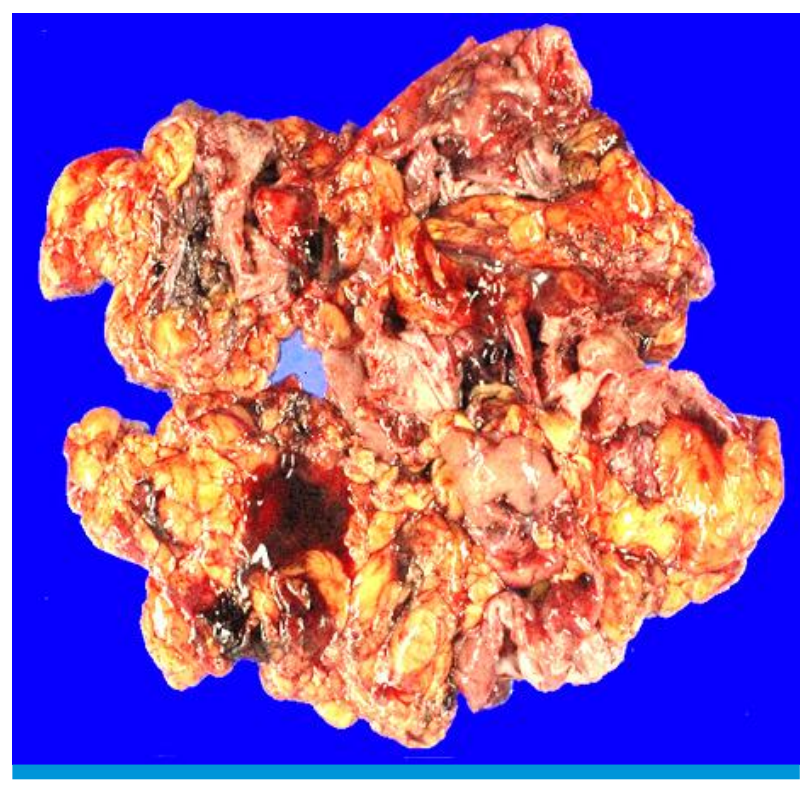

Fig. 6. Laparoscopically removed left kidney specimen showing fragments of cystic wall with attached fibroadipose tissues. abdominal pain in 1 of $100^{12}$. Fewer cases with delayed diagnosis as our case were presented with progressive abdominal distension. Similar to our case, Dahniya et al reported a 7-year-old female with giant pelviureteric hydronephrosis presenting progressive abdominal distension ${ }^{13}$. Hsieh et al also reported GH in a 7-year-old girl presenting distended abdomen ${ }^{14}$. In our case, there was no history of abdominal pain or recurrent vomiting, but frequent defecation over 3 times a day right after food intake. The parents assumed the abnormal bowel habit with abdominal distension and DOE of the patient were obesity-related.

First approach to suspected hydronephrosis in children is sonography to confirm the diagnosis, but hydronephrosis may be confused with other masses of kidney such as renal tumor, retroperitoneal tumor, pseudomyxoma and so on. In such cases, CT or MR images are helpful to make a differential diagnosis ${ }^{6,8}$.

Hydronephrosis due to UPJ obstruction can be treated surgically with various procedures such as pyeloplasty, nephrectomy, and percutaneous nephrostomy placement. Standard therapy for UPO obstruction is open dismembered pyeloplasty. Since the first procedure in 1949, the success rate of pyeloplasty in UPJ obstruction has increased to $>95 \%{ }^{15)}$. However, in long-established and severe hydronephrotic cases with no residual renal function, total nephrectomy is done in general ${ }^{2}$. The practical goal of surgical treatment is to salvage kidney that has more than 10-15\% of total renal function ${ }^{16}$. According to $99 \mathrm{mTc}$-DMSA renal scintigraphy in this case, the relative renal function of the left kidney was $24.8 \%$, however, we performed laparoscopic total nephrectomy. Because we thought the renal function was overestimated due to the abnormally wide region of interest (ROI) of the left kidney set for the scan, which could have included excessive background radioisotope activity. Furthermore, 99mTc-MAG3 renal scintigraphy showed delayed radioisotope uptake up to 50 minutes in left kidney, thus, considered almost nonfunctional.

Drainage procedure may be practiced in cases when the renal function improvement is expected through hemodynamic changes acquired by decompression ${ }^{9}$. Acute renal failure and cardiopulmonary distress may occur after sudden removal of more than $3 \mathrm{~L}$ of fluid, as a result of sudden abdominal decompression. Therefore, patients undergoing percutaneous nephrostomy for massive hydronephrosis 
need to be observed carefully during and after procedure ${ }^{3,17)}$. There are limited data on the long term outcome of children with UPJ obstruction who underwent pyeloplasty, especially in GH. Braga et al reported 5\% of the 401 children who underwent open pyeloplasty required additional surgery for increasing hydronephrosis due to recurrent obstruction $^{18)}$.

In spite of the widespread use of prenatal ultrasound and the development of new diagnostic techniques, GH still remains asymptomatic and is found sporadically in all age groups $^{2)}$. In this case, the hydronephrotic left kidney could have been saved if the patient came to the hospital and took a sonographic examination earlier. Delayed diagnosis in this case was attributedby the patient's symptoms overlapping with those of obesity.

We believe that the cause of DOE and abdominal distension in this case was mainly due to $\mathrm{GH}$ rather than obesity or asthma, because the patient is free from the symptoms. In conclusion, we propose that $\mathrm{GH}$ should be considered as one of the etiologies of dyspnea and abdominal distension in children.

\section{Conflicts of interest}

No potential conflict of interest relevant to this article was reported.

\section{References}

1. Tazi MF, Riyach O, Ahallal Y, Mellas S, Khallouk A, El Fassi MJ, et a I. Giant urinary bladder and bilateral giant hydronephrosis due to bladder neck obstruction: One case report and literature review. Case Reports in Urology 2012.

2. Yapanoglu T, Alper F, Ozbey I, Aksoy Y, Demirel A.Giant hydronephrosis mimicking an intraabdominal mass. Turkish Journal of Medical Sciences 2007;3:177-9.

3. Chiang $\mathrm{PH}$, Chen MT, Chou YH, Chiang $\mathrm{CP}$, Hwang $\mathrm{CH}$, Chien $\mathrm{CH}$. Giant hydronephrosis: report of 4 cases with review of the litera- ture. J Fomos Med Assoc 1990; 89:811-7.

4. Tombari AA, Power RF, Harper JM, Politano VA. Giant hydronephrosis: a case report with review of literature. J Urol 1968;38:1203.

5. Baik HK, Park UC, Kim HS, Park DC, Cho HG, Cho JY, et al. A case of Giant hydronephrosis in children. The Kon-kuk J of Medical Sciences 1993;3.

6. Yılmaz E, Guney S. Giant hydronephrosis due to ureteropelvic junction obstruction in a child. CT and MR appearances. Clinical Imaging 2002;26(2):125-8.

7. Ardicoglu A, Yuzgec V, Atikeler MK, Özdemir E. Case of adultgiant hydronephrosis as unusual cause of intraabdominal mass. InternationalUrology and Nephrology. 2003;35:7-8.

8. Fukasawa M, Kobayashi H, Matsushita K, Araki I, Takeda M. Intraperitoneal rupture of giant hydronephrosis due to ureteralcancer accompanied by renal cell carcinoma. J of Urology 2002;167:1 393-4.

9. Wang QF, Zeng G, Zhong L, Li QL, Che XY, Jiang T, et al. Giant hydronephrosis due to ureteropelvic junction obstruction: A rare case report, and a review of the literature. Molecular and Clinical Oncology 2016;5 (1):19-22.

10. Rooks VJ, Lebowitz RL. Extrinsic ureteropelvic junction obstruction from a crossing renal vessel: demography and imaging. Pediatric Radiology 2001;31:120-4.

11. James L. Homme, Ashley A. Foster. Recurrent severe abdominal pain in the pediatric patient". J of Emergency Medicine. 2014;5: 627-31.

12. Williams B, Tarren B, Resnick MI. Pathophysiology and treatment of ureteropelvic junction obstruction. Current Urology Reports 2007; 8:111-7.

13. Dahniya MH, Rathi AK, Ahmad R. Giant pelviureteric hydronephrosis in a child. Pediatric Radiology 1988;18:501-2.

14. Hsieh MY, Ku MS, Tsao TF, Chen SM, Chao YH, Tsai JD, et al. Rare case of atrophic ectopic kidney with giant hydronephrosis in a 7-year-old girl. Urology 2013; 81(3):655-8.

15. Hashim H. Woodhous CRJ. Ureteropelvic junction obstruction. Eur Urol Suppl 2012;11:25-32.

16. Harper JD, Shah SK, Baldwin DD, Moorhead JD. Laparoscopic nephrectomy for pediatric giant hydronephrosis. Urology 2007; 70(1):153-6.

17. Grover CA, Crisp JG. Giant hydronephrosis presenting as an acute abdomen. J Emerg Med 2012;5:e307-10.

18. Braga LH, Lorenzo AJ, Bagli DJ. Risk factors for recurrent ureteropelvic junction obastruction after open pyelplasty in an large pediatric cohort. J of Urology 2008;180:1684. 